\title{
Videogames: opportunities for learning
}

\author{
María-Esther Del-Moral \\ Faculty of Teacher Training and Education, University of Oviedo, Spain \{emoral@uniovi.es\} \\ Received on 20 November 2013; revised on 23 November 2013; accepted on 14 December 2013; published on 15 January 2014
}

DOI: $10.7821 /$ naer.3.1.1

We find ourselves at a turning point where the barriers of digital leisure have become blurred, to which must be added that this phenomenon is not confined to a single age group. Play invades nearly everything; gaming and videogames are acquiring considerable prominence in our everyday life. This is a clearly emergent cultural industry: 'videogame developer' has now become a highly sought-after profile in numerous fields, from advertising to education. An increasingly high number of applications are hosted on social networks, thus allowing users to participate and share games with others.

In turn, the most apocalyptic postulates which regarded videogames as a source of addictions and reprehensible behaviors -especially those which stand out for their violent contents- have been left behind in the psycho-educational sphere, in order to try and rescue the opportunities offered by many other videogames for the acquisition and development of specific skills. Furthermore, regulation systems such as the PEGI code currently serve as a reference for parents and educators to be able to select commercial videogames according to their themes.

Without a doubt, some commercial videogames -as well as the so-called serious games- can be considered interesting scenarios for the promotion of various learning formats, also informally. However, the utilization of videogames for educational purposes in formal contexts is a practice that requires not only a previous selection or assessment but also a systematic planning to reach the foreseen training goals, favoring subjects' cognitive development for the mastery of problem-solving skills, and for the acquisition of multiple strategies.

Videogame designs are growingly realistic, which turns them into ludic environments that can recreate highly inspirational learning situations, allowing subjects to interact and immerse themselves in adventures from the ingenious challenges which are proposed to them, while they simultaneously develop their digital competences or skills; hence the need for schools to avoid being left out of the advantages which these technological instruments so widely used by young people can provide.

The present monographic issue thus collects different research works focused on videogames which adopt very diverse methodologies and have been developed in different intervention contexts.

Firstly, the article "Virtual Communities in a secondary school -Discovering the internal grammar of videogames" shows an ethnographic study which describes the monitoring of a workshop carried out in secondary educational classrooms with videogames -as instruments that can favor new literacy campaigns- analyzing the debates generated by players integrated into a virtual community.
The next article, "CityVille: collaborative game play, communication and skill development on social networks" is presented as a research initiative focused on the opportunities offered by an online videogame hosted on Facebook when it comes to favoring collaborative play between videoplayers and encourage communication between them, in addition to identifying the skills which these players believe to have developed playing this game on social networks.

Another article -"Can videogames be used to develop the curriculum of the infant education stage?"- examines the perception that future teachers from the degree in Infant Education have about the value of videogames as useful instruments in the curricular development of infant students, after attending training sessions about their didactic utilization.

A further step is taken with the article "The Theory of Evolution and natural selection: learning through play and reflection", which describes the implementation of an innovative experience with the commercial game Spore in Secondary Education with the aim of strengthening the scientific contents linked to the evolution of species.

From a different perspective, "Graphics, playability and social interaction: the greatest motivations to play Call of Duty. Educational reflections" undertakes research on the influence exerted by graphic design and the resources guaranteeing game playability and social interaction in the controversial war videogames - such as Call of Duty - as success factors which ensure player motivation, complemented with a number of interesting reflections from the educational point of view.

Finally, the article "Proposal for the assessment of generic competences using a serious game" describes a research study focused on the design of a serious game oriented to the teaching and assessment of generic competences among university students; more precisely, problem solving and entrepreneurship.

The typology of studies about videogames aimed at training is obviously broad and complex. With no desire whatsoever to exhaust it, the Journal NAER sets itself the aim of presenting a fascinating as well as innovative field of research which makes necessary a rigorous, in-depth analysis that can allow us to shed light and provide scientific evidence that can contribute to show the advantages and opportunities that videogames offer as resources which go beyond the merely ludic aspect.

$\mathrm{M}^{\mathrm{a}}$ Esther del Moral Pérez 